\title{
Sero-positivity rate of rubella and associated factors among pregnant women attending antenatal care in Mwanza, Tanzania
}

\author{
Berno Mwambe ${ }^{1 \dagger}$, Mariam M Mirambo ${ }^{2 \dagger}$, Stephen E Mshana ${ }^{2 *}$, Anthony N Massinde, Benson R Kidenya ${ }^{3}$, \\ Denna Michael ${ }^{4}$, Domenica Morona ${ }^{2}$, Charles Majinge ${ }^{1}$ and Uwe Groß ${ }^{5}$
}

\begin{abstract}
Background: Sero-positivity rates of the rubella virus among pregnant women vary widely throughout the world. In Tanzania, rubella vaccination is not included in the national immunization schedule and there is therefore no antenatal screening for this viral disease. So far, there are no reports on the sero-prevalence of rubella among pregnant women in Tanzania. As a result, this study was undertaken to establish the sero-positivity rate of rubella and rubella risk factors among pregnant women attending antenatal care clinics in Mwanza, Tanzania.

Methods: From November 2012 to May 2013 a total of 350 pregnant women were enrolled and their serum samples collected and analyzed using the AXSYM anti-rubella virus IgG/IgM-MEIA test. Demographic and clinical data were collected using a standardized data collection tool. Data analysis was done using STATA version 12.

Results: Of 342 pregnant women tested for rubella antibodies, 317 (92.6\%) were positive for anti-rubella lgG while only $1(0.3 \%)$ was positive for $\mathrm{lgM}$. Higher sero-positivity rates were found in the age group of 25-44 years. Furthermore, it was observed that with each year increase in age, the risk of contracting rubella increases by $12 \%(\mathrm{OR}=1.12,95 \% \mathrm{Cl}$ : 1.02-1.22, $\mathrm{P}=0.019$ ). Women involved in farming and business women were at a higher risk of contracting rubella infection compared to formally employed women (OR: 4.9, $\mathrm{P}=0.011 ; \mathrm{OR} 7.1, \mathrm{p}=0.003$ respectively). In univariate analysis, the risk of contracting rubella virus infection was found to increase with gestational age with a statistical significance.
\end{abstract}

Conclusions: Sero-positivity rates of rubella are high in Mwanza and are significantly associated with an increase in age and being a farmer or a business woman. Screening of rubella and immunization of women at risk are highly recommended in this area with a high non-immune rate against rubella virus.

Keywords: Prevalence, Rubella, Pregnancy, Mwanza, Tanzania

\section{Background}

Rubella is habitually a self-limiting disease. However, if contracted during pregnancy, it may result in miscarriage, stillbirth or an infant born with congenital rubella syndrome (CRS), characterized by deafness, heart disease, cataracts or other permanent congenital manifestations [1,2]. In developing countries, more than 100,000 children are born with CRS each year $[2,3]$. The sero-positivity for rubella among pregnant women varies widely in different

\footnotetext{
* Correspondence: mshana72@yahoo.com

${ }^{\dagger}$ Equal contributors

${ }^{2}$ Department of Microbiology/Immunology, Catholic University of Health and Allied Sciences, Box 1464, Mwanza, Tanzania

Full list of author information is available at the end of the article
}

countries. As a matter of fact, in many developing countries, rubella sero-positivity among pregnant women has been reported to range from $54.1 \%$ to $95.2 \%[1,2,4,5]$. Clinical diagnosis of rubella during pregnancy proves difficult as only approximately $50 \%$ of the infected people present with typical exanthematous skin lesions $[1,6]$. Hence, serological screening of rubella, based on the detection of IgG and IgM antibodies, remains the mainstay for diagnosis [3]. Since no specific treatment exists for rubella, vaccination before pregnancy is the only mean to prevent congenital infection. In developed countries, rubella infections are indeed prevented by active immunization given as part of a MMR vaccine [6]. WHO recommends that susceptible pregnant women be vaccinated as soon as

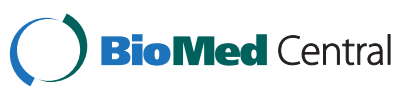


possible during the postpartum period. However, in Tanzania, rubella vaccination is not included in the national immunization programme [2].

In Tanzania and other neighbouring countries, there are no screening programs for rubella among pregnant women and the magnitude of the problem is therefore unknown. This study was carried out to determine the sero-positivity rates and the predictors of rubella infection among pregnant women attending antenatal clinics in Mwanza, Tanzania.

\section{Methods}

This was a cross-sectional study conducted between November 2012 and May 2013 in Mwanza city, Tanzania. The study involved three antenatal care clinics: UMATI and Sekou-Toure Regional Hospital, located in an urban area, and Igombe Health Centre, located in a rural setting. The sample size of 322 was calculated using a formula suitable for cross-sectional studies $[7,8]$. The study enrolled 350 pregnant women from the 3 clinics individual sample size for each clinic was a proportion of the total sample size calculated on the basis of the number of pregnant women, attending those clinics.

\section{Data collection and laboratory procedures}

Data were collected using a standardized data collection tool. Information on socio-demographic characteristics and relevant medical and obstetric characteristics were gathered. About $4 \mathrm{ml}$ of venous blood was taken from each participant. A total of 350 samples were collected: $\mathrm{n}=180$, in Igombe (rural area) and $\mathrm{n}=170$ in UMATI and Sekou-Toure (urban area). All samples were transported to the Bugando Medical Centre, where the serum was separated from the whole blood. The obtained serum samples were numbered and kept at $-80^{\circ} \mathrm{C}$ until transportation to Germany for subsequent analysis of rubella-specific IgG and IgM antibodies using AxSYM rubella virus IgG/IgM-MEIA (Abbott, IL, USA). Manufacturer reference values for positive results were anti-rubella IgG $\geq 10 \mathrm{IU} / \mathrm{ml}$ and anti-rubella IgG $<10 \mathrm{IU} / \mathrm{ml}$ for negative results while anti-rubella IgM $>0.8$ was considered as positive and anti-rubella $\operatorname{IgM}<0.6$ as negative. An $\operatorname{IgM}$ value between 0.6-0.8 was considered as borderline.

\section{Data analysis}

The programme Microsoft Office Excel 2007 was used to enter the data according to codes given and data were analyzed using the STATA version 12 (College Station, Texas, USA). Categorical variables were summarized as proportions and were analyzed using the Pearson's Chisquare test to observe the differences among the various groups. Continuous variables were summarized as median with interquartile range. Univariate analysis and multivariate logistic regression models were fitted to determine the predictors of rubella infection. Predictors with p-value less than 0.2 were fitted into the multivariate logistic regression analysis and their odds ratios and 95\% confidence interval were noted. Predictors with p-value of less than 0.05 were considered statistically significant.

\section{Ethical approval}

The study protocol was approved by the CUHAS/BMC Ethics Review Board. An informed written consent was sought from each pregnant woman prior to her enrolment.

\section{Results}

Out of the 350 enrolled women, 342 had a valid analysis for rubella infection and were included in the final analysis. The median maternal age of the participants was 25 years. A total of 181 (52.9\%) pregnant women were from rural areas and 32 (9.3\%) of all pregnant women were employed. Fifty-five (55\%) and $40 \%$ of the women were in their second and third trimester of pregnancy respectively. Eighty-five percent $(85 \%)$ of the women were married (Table 1$)$.

Table 1 Distribution of rubella sero-prevalence along with demographic characteristics among pregnant women, Mwanza, 2013

\begin{tabular}{|c|c|c|c|c|c|}
\hline \multirow{3}{*}{ Characteristic } & \multicolumn{4}{|c|}{ Rubella sero-status $(\mathrm{N}=342)$} & \multirow[t]{3}{*}{ Total } \\
\hline & \multicolumn{2}{|c|}{ Sero-positivity } & \multicolumn{2}{|c|}{ Sero-negativity } & \\
\hline & n & $\%$ & $\mathrm{n}$ & $\%$ & \\
\hline \multicolumn{6}{|l|}{ Age (Yr) } \\
\hline $15-24$ & 152 & 89.4 & 18 & 10.6 & 170 \\
\hline $25-34$ & 142 & 95.9 & 6 & 4.1 & 148 \\
\hline $35-44$ & 23 & 95.8 & 1 & 4.2 & 24 \\
\hline \multicolumn{6}{|l|}{ Residence } \\
\hline Urban & 146 & 90.6 & 15 & 9.4 & 161 \\
\hline Rural & 171 & 94.5 & 10 & 5.0 & 181 \\
\hline \multicolumn{6}{|l|}{ Occupation } \\
\hline Business & 90 & 93.8 & 6 & 6.3 & 96 \\
\hline Farmer & 202 & 94.4 & 12 & 5.6 & 214 \\
\hline Employed & 25 & 78.1 & 7 & 21.9 & 32 \\
\hline \multicolumn{6}{|l|}{ Education } \\
\hline Illiterate & 18 & 85.7 & 3 & 14.3 & 21 \\
\hline Primary & 219 & 92.4 & 18 & 7.6 & 237 \\
\hline Secondary+ & 80 & 95.2 & 4 & 4.8 & 84 \\
\hline \multicolumn{6}{|l|}{ Marital status } \\
\hline Married & 269 & 93.1 & 20 & 6.6 & 289 \\
\hline Unmarried & 48 & 90.6 & 5 & 9.4 & 53 \\
\hline \multicolumn{6}{|l|}{ Trimester } \\
\hline 1st Trimester & 13 & 81.2 & 3 & 18.8 & 16 \\
\hline 2nd Trimester & 171 & 90.9 & 17 & 9.1 & 188 \\
\hline 3rd Trimester & 133 & 96.3 & 5 & 3.7 & 138 \\
\hline
\end{tabular}


Of the 342 women with valid results, 317 (92.6\%) were tested positive for anti-rubella IgG while only 1 (0.3\%) was positive for IgM, indicating an acute infection with the rubella virus. A total of 25 women $(7.3 \%)$ had a IgG titre of less than $10 \mathrm{IU}$, thus being at risk of contracting rubella infection during pregnancy. The sero-positivity rate was slightly higher among pregnant women residing in rural than in urban areas (94.5\% vs. $90.6 \%)$ but this difference was not statistically significant (OR 1.7, 95\% (0.77-4.03, $\mathrm{p}=0.183)$. A higher prevalence of rubellaspecific IgG antibodies was observed in the age group 25-34 than in the age group 15-24. It was observed that as the age increases by one year the risk of contracting rubella increases by $12 \%(\mathrm{OR}=1.12,95 \%$ CI 1.02-1.22, $\mathrm{p}=0.019$ ) (Table 2, Figure 1). Farmers and business women had significantly higher sero-positivity rates than employed women (OR 4.9, $\mathrm{p}=0.011$; OR 7.1, $\mathrm{p}=0.003$ respectively) \{Table 2\}. No statistical difference was observed between sero-positivity and gravidity (OR 0.9 , 95\% CI $0.6-1.4, \mathrm{p}=0.561$ ) while the risk of contracting rubella was higher in the third trimester than in the first and second trimesters (OR 6.1, 95\% CI 1.3-28.6, p = 0.021). Similar findings were obtained when gestational age (GA) was analyzed as a continuous variable: the median GA was higher for positive women than for negative women (26 vs. 21; OR 1.1, 95\% CI 0.99-1.1.12, $\mathrm{p}=0.055$ ).

\section{Discussion}

To the best of our knowledge, this is the first study in Tanzania to provide rubella sero-prevalence data among pregnant women attending prenatal care clinics. In
Tanzania and neighbouring countries (Kenya, Uganda, Burundi, Democratic Republic of Congo) there are no rubella immunization programmes, and routine rubella screening during pregnancy is not practiced. The seroprevalence of $92.6 \%$ in Mwanza is very high, suggesting a continuous transmission of endemic rubella virus in the region. The reported sero-prevalence in this study is higher than $85.8 \%, 77 \%$, and 53\% reported from Southern Italy [9], Ouagadougou-Burkina Faso [8], Benin-Niger [10], Sudan [11], Taiwan [12] and Nigeria [13]. When categorized by age, the sero-positivity rate of $89 \%$ for the age group 15-25 years is lower than 94\% observed in Kenya [14] for age group 14-20 years. No study was found in Uganda investigating the sero-positivity of rubella among pregnant women but the sero-positivity in our study is lower than the one reported among health workers in Uganda [15] whereby $98 \%$ of them were rubella seropositive. These data suggest that there is a high transmission rate of the rubella virus in East Africa. As in previous African studies [16,17], a low rate of acute infections was found in the current study. However, this might not reflect the true picture as women were not screened during early pregnancy and followed-up. The seroprevalence in various trimesters is still higher than that from other African countries with no immunization programme $[11,13,14,18,19]$.

The current study indicates that a considerable number of pregnant women in Mwanza are at risk of acquiring primary infection with the rubella virus. There is no vaccination against rubella, either in the public or private sector in Mwanza, or anywhere in Tanzania. In

Table 2 Risk factors associated with Rubella infection among pregnant women $(\mathbf{N}=342)$ in Mwanza, 2013

\begin{tabular}{|c|c|c|c|c|c|c|}
\hline \multirow[t]{2}{*}{ Character } & \multicolumn{2}{|c|}{ Sero-status } & \multicolumn{2}{|c|}{ Crude } & \multicolumn{2}{|c|}{ Adjusted } \\
\hline & $\begin{array}{c}\text { Positive } \\
\text { n (\%) }\end{array}$ & $\begin{array}{c}\text { Negative } \\
\text { n (\%) }\end{array}$ & OR $(95 \% \mathrm{Cl})$ & p-value & OR $(95 \% \mathrm{CI})$ & p-value \\
\hline${ }^{* \dagger}$ Age & 25 [22-29] & 23 [19-25] & $1.1(1.02-1.22)$ & 0.019 & $1.2(1.02-1.33)$ & 0.021 \\
\hline \multicolumn{7}{|l|}{${ }^{+}$Residence } \\
\hline Urban & $146(90.7)$ & $15(9.3)$ & 1 & & & \\
\hline Rural & 171 (94.5) & $10(5.5)$ & $1.7(0.77-4.01)$ & 0.183 & $2.1(0.7-6.7)$ & 0.191 \\
\hline \multicolumn{7}{|l|}{${ }^{\dagger}$ Occupation } \\
\hline Employed & $25(78.1)$ & 7 (21.9) & 1 & & 1 & \\
\hline Farmers & $202(94.4)$ & $12(5.6)$ & $4.7(1.7-13.1)$ & 0.003 & $4.9(1.4-16.6)$ & 0.011 \\
\hline Business & $90(93.8)$ & $6(6.3)$ & $4.2(1.3-13.6)$ & 0.017 & $7.1(1.9-26.3)$ & 0.003 \\
\hline${ }^{*}$ Gravidity & $2[1-4]$ & $2[1,2]$ & $1.4(0.99-1.86)$ & 0.057 & $0.9(0.6-1.4)$ & 0.561 \\
\hline \multicolumn{7}{|l|}{ Trimester } \\
\hline $1 \mathrm{st}$ & $13(81.2)$ & $3(18.8)$ & 1 & & & \\
\hline 2nd & $171(91.0)$ & $17(9.0)$ & $2.3(0.6-8.9)$ & 0.222 & - & - \\
\hline $3 r d$ & 133 (96.4) & $5(3.60)$ & $6.1(1.3-28.6)$ & 0.021 & & \\
\hline${ }^{*}$ Gestational age & $26[20-32]$ & $21[18-26]$ & $1.1(1.001-1.12)$ & 0.046 & $1.1(0.99-1.12)$ & 0.055 \\
\hline
\end{tabular}

*Median; ${ }^{\dagger}$ Factors adjusted for. 


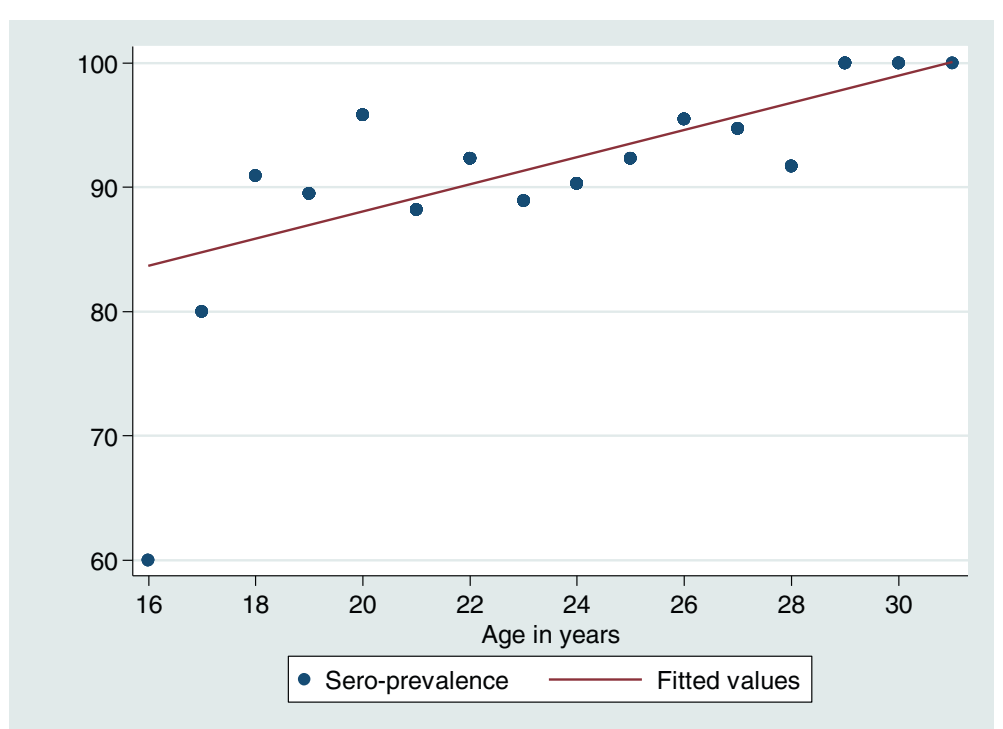

Figure 1 Age specific Sero-prevalence of rubella infections. There is an increase of sero-prevalence of rubella infection with an increase in age. The sero-prevalence increases by $1.6 \%$ with one year increase in age. The risk (odds ratios) of acquiring rubella infection increases by $12 \%$ with one year increase in age.

Mwanza, $11 \%$ of the women who are becoming pregnant at an age between $15-24$ are at risk of contracting the rubella virus therefore being at an increased risk of CRS $[1,17,18]$. Overall, $7.3 \%$ of the women of Mwanza are at risk of acquiring primary rubella infection during pregnancy. This is higher than the figure of $7 \%$ observed in Eldoret Kenya [19] and necessitates the introduction of prenatal screening and routine immunization of all women at risk. Both Kenya and Tanzania do not have rubella immunization programme therefore the high sero-positivity rates found in Eastern African countries might be due to high transmission rates of infection. Since there is no treatment for an active infection during pregnancy, screening and immunization of women at risk is the mainstay of preventing CRS [2]. Policy makers should therefore consider implementing the above mentioned strategies.

In the present study, as in a South African one [18], it was noted that women involved in business and farming activities are a higher risk of acquiring rubella infection compared to formally employed women. A high social economic status, which implies good living conditions, has been found to be associated with a lower risk to acquire rubella infection [20]. As in studies undertaken in Kenya $[14,19]$, an increase in age was associated with an increase in rubella sero-positivity. A large proportion of women in Tanzania are involved in farming activities and reside in villages, and they also tend to have their first pregnancy at a low age (15-24). All these factors, as evidenced by this study, put them at risk of acquiring rubella infection and consequently increase the risk of developing CRS. In the current study, the third trimester was a risk of IgG sero-positivity, as demonstrated by univariate analysis. It was also noted that as GA increases the IgG sero-positivity increases. This indicates that women of this geographical area may be contracting acute rubella infection in early pregnancy. Further investigations are required to follow up these women for possible CRS.

Due to the cross-sectional nature of the study design, follow-up of the participants was not undertaken. This is an important limitation. However, the study established the magnitude and some of the factors associated with rubella sero-prevalence and recommended future studies.

\section{Conclusion}

Sero-positivity of rubella is high in the Mwanza region with a significant proportion of women at risk of contracting primary rubella infection. Advanced age and being a woman involved in farming or a business woman were independent risk factors associated with positive rubella infection. Screening for rubella infection during antenatal care and post-natal immunization of women at risk should be considered in Tanzania, as a major strategy to minimize CRS. Susceptible pregnant women should be thoroughly evaluated for possible rubella infection. Women who were immune in their first pregnancy should not be vaccinated, as they have naturally acquired immunity. In addition to the above interventions, defining the target population age for rubella vaccination is a key issue. An efficient programme for selective immunization of pre-pubertal/adolescent girls should be considered, possibly as a critical component of the school health system. A future study including 
children and adolescents of various ages would allow the identification of the most susceptible time frame of infection in Tanzania. We also strongly recommend a large follow up study of pregnant women to determine the outcome of the pregnancy and the magnitude of CRS in our settings.

\section{Competing interests}

The authors declare that they have no competing interests.

\section{Authors' contributions}

$\mathrm{BM}, \mathrm{MM}, \mathrm{SEM}, \mathrm{CM}$ and UG participated in the design of the work. BM and AM participated in the collection of specimens and clinical data. UG analyzed the sample. BM, MM, BRK, DM, DM and SEM analyzed and interpreted the data. SEM wrote the first draft of the manuscript which was approved by all authors.

\section{Acknowledgement}

The authors would like to acknowledge the technical support provided by Bernard Okamo and the technical staff of the Institute of Medical Microbiology Göttingen. We thank all staff in UMATI, Sekou-Toure and Igombe for their technical support.

\section{Author details}

Department of Obstetrics and Gynaecology, Catholic University of Health and Allied Sciences, Box 1464, Mwanza, Tanzania. ${ }^{2}$ Department of Microbiology/Immunology, Catholic University of Health and Allied Sciences, Box 1464, Mwanza, Tanzania. ${ }^{3}$ Department of Biochemistry and Molecular Biology, Catholic University of Health and Allied Sciences, Box 1464, Mwanza, Tanzania. ${ }^{4}$ National Institute of Medical Research Mwanza, Ocean Road, P.O. BOX 9653, Dar es salaam 2448, Tanzania. ${ }^{5}$ Institute of Medical Microbiology, Göttingen University Medical Center, Göttingen, Germany.

Received: 17 June 2013 Accepted: 26 February 2014

Published: 3 March 2014

\section{References}

1. Shah I, Bhatnagar S: Antenatal diagnostic problem of congenital rubella. Indian J Pediatr 2010, 77:450-451.

2. WHO: Rubella vaccines: WHO position paper. Wkly Epidemiol Rec 2011, 86(29):301-316.

3. Binnicker MJ, Jespersen JD, Harring JA: Multiplex detection of IgM and IgG class antibodies to Toxoplasma gondii, rubella virus, and cytomegalovirus using a novel multiplex flow immunoassay. Clin Vaccine Immunol 2010, 17(11):1734-1738.

4. Linguissi LS, Nagalo BM, Bisseye C, Kagone TS, Sanou M, Tao I, Benao V, Simpore J, Kone B: Seroprevalence of toxoplasmosis and rubella in pregnant women attending antenatal private clinic at Ouagadougou, Burkina Faso. Asian Pac J Trop Med 2012, 5(10):810-813.

5. Uyar Y, Balci A, Akcali A: Prevalence of rubella and cytomegalovirus antibodies among pregnant women in Northern Turkey. New Microbiol 2008, 31:451-455.

6. Usonis V, Anca I, Andre F: Rubella revisited: where are we on the road to disease elimination in Central Europe? Vaccine 2011, 29:9141-9147.

7. Cochran WG: Sampling Techniques. 2nd edition. New York: John Wiley and Sons, Inc; 1963.

8. Doehring E, Reiter-Owona I, Bauer O, Kaisi M, Hlobil H, Quade G, Hamudu NA, Seitz HM: Toxoplasma gondii antibodies in pregnant women and their newborns in Dar es Salaam, Tanzania. Am J Trop Med Hyg 1995, 52:546-548.

9. Calimeri CA, La Fauci V, Squeri R, Grillo OC, Lo Giudice D: Prevalence of serum anti-rubella virus antibodies among pregnant women in southern Italy. Int J Gynaecol Obstet 2012, 116(3):211-213.

10. Onakewhor JU, Chiwuzie J: Seroprevalence survey of rubella infection in pregnancy at the University of Benin Teaching Hospital, Benin City, Nigeria. Niger J Clin Pract 2011, 14(2):140-145.

11. Hamdan HZ, Abdelbagi IE, Nasser NM, Adam I: Seroprevalence of cytomegalovirus and rubella among pregnant women in western Sudan. Virol J 2011, 11(8):217.
12. Lin C, Yang C, Shih Y, Hsu H, Yang T, Cheng Y, Chang CF, Hsieh LC, Chen $\mathrm{BH}$, Lee $\mathrm{CH}$, Huang YL: Rubella Seroepidemiologic and estimations of the catch-up immunisation rate and persistence of antibody titers in pregnant women in Taiwan. BJOG 2011, 118:706-712.

13. Bukbuk DN, el Nafaty AU, Obed JY: Prevalence of rubella-specific lgG antibody in non-immunized pregnant women in Maiduguri, north eastern Nigeria. Cent Eur J Public Health 2002, 10(1-2):21-23.

14. Kombich JJ, Muchai PC, Tukei P, Borus PK: Rubella seroprevalence among primary and pre- primary school pupils at Moi's Bridge location, Uasin Gishu District, Kenya. BMC Public Health 2009, 29(9):269.

15. Lewis RF, Braka F, Mbabazi W, Makumbi I, Kasasa S, Nanyunja M: Exposure of Ugandan health personnel to measles and rubella: evidence of the need for health worker vaccination. Vaccine 2006, 24(47-48):6924-6929.

16. Tahita MC, Hübschen JM, Tarnagda Z, Ernest D, Charpentier E, Kremer JR, Muller CP, Ouedraogo JB: Rubella seroprevalence among pregnant women in Burkina Faso. BMC Infect Dis 2013, 13:164.

17. Schoub BD, Harris BN, McAnerney J, Blumberg L: Rubella in South Africa: an impending Greek tragedy? S Afr Med J 2009, 99:7.

18. Robertson SE, Featherstone DA, Gacic-Dobo M, Hersh BS: Rubella and congenital rubella syndrome: global update. Rev Panam Salud Publica 2003, 14(5):306-315.

19. Kombich JJ, Muchai PC, Borus PK: Seroprevalence of natural rubella antibodies among antenatal attendees at Moi teaching and Referral Hospital, Eldoret, Kenya. J Immunol Tech Infect Dis 2012, 1:1. doi:10.4172/ 2325-9752.1000102.

20. Corcoran C, Hardie DR: Seroprevalence of rubella antibodies among antenatal patients in the Western Cape. S Afr Med J 2005, 95(9):688-690.

doi:10.1186/1471-2393-14-95

Cite this article as: Mwambe et al:: Sero-positivity rate of rubella and associated factors among pregnant women attending antenatal care in Mwanza, Tanzania. BMC Pregnancy and Childbirth 2014 14:95.

\section{Submit your next manuscript to BioMed Central and take full advantage of:}

- Convenient online submission

- Thorough peer review

- No space constraints or color figure charges

- Immediate publication on acceptance

- Inclusion in PubMed, CAS, Scopus and Google Scholar

- Research which is freely available for redistribution 